\section{EMPREENDEDORISMO URBANO: ENTRE O DISCURSO E A PRÁTICA}

Rose Compans

São Paulo: Editora Unesp, 2005.

Juliano Pamplona Ximenes Ponte

Arquiteto e Urbanista, doutorando do IPPUR-UFRJ.

A concepção de que nossas cidades e regiōes devam competir entre si e atrair investimentos é, hoje, hegemônica. Uma crítica a tal concepção pressupõe uma predisposição à desconstrução de pré-noções - ao mesmo tempo uma postura metodológica e uma abertura ao movimento entre o concreto e o abstrato, na análise histórica. A crítica da adoção, cada vez mais freqüente, do Planejamento Estratégico no âmbito do Planejamento Urbano e Regional faz parte dessa desconstrução.

No campo do Planejamento em geral, as concepções estratégicas passaram a circular, disseminando conceitos e fundamentando consultorias destinadas ao aparato estatal. A crítica do Planejamento Estratégico, por sua vez, colocou para si o desafio, ao mesmo tempo, de empreender esforço teórico e análise aplicada das práticas que ele sustenta. É desse duplo exercício que foi elaborado o livro Empreendedorismo urbano, de Rose Compans, resultante da tese de doutoramento que recebeu o Prêmio Brasileiro "Política e Planejamento Urbano e Regional”, da ANPUR em 2003.

Destaca-se no trabalho, em primeiro lugar, a intenção de sistematizar o debate político e econômico do desenvolvimento urbano recente no que tange às novas estratégias de desenvolvimento territorial. Em seguida, a preocupação de situar tais estratégias historicamente, relativizando o Planejamento Estratégico como "teoria" e "técnica" de intervenção nos sistemas urbanos. Por fim, o esforço de aplicar a análise ao caso do município do Rio de Janeiro, dele extraindo especificidades, limites e possibilidades.

Contextualizando o debate, Compans sustenta que a adoção da idéia de "governança urbana" e de "planejamento estratégico de cidades" não exprimiria apenas a emergência de novas técnicas de gestão urbana e ordenamento territorial. Seria, antes, parte de uma nova forma de modernização capitalista, baseada em alterações na espacialidade da cidade, na redução de riscos ao investidor privado e na eliminação dos cons- trangimentos à acumulação, além de uma alteração social da própria base produtiva.

A análise econômica é então acionada, principalmente, a partir da escola francesa da regulação, tratando do rearranjo espacial/locacional da produção e do papel substancial dos chamados serviços avançados na economia contemporânea. Apesar dos aventados efeitos de "reestruturação" do capital, a autora contesta a idéia de um capital totalmente "desterritorializado", quase etéreo, como parecem acreditar certos autores. Haveria mesmo o reforço do papel das estruturas materiais, físicas (tecnologias e infra-estruturas de transportes e telecomunicações, por exemplo) na reconfiguração dos capitais fixos dispostos no território.

Outra questão é a do papel do poder local. Considerado por alguns como mais próximo das demandas territoriais específicas e, ao mesmo tempo, capaz de promover articulaçôes políticas e intersetoriais, o poder local torna-se quase um fetiche, sendo objeto de discursos propositivos dos defensores do planejamento estratégico de cidades. O poder local, nesses discursos, seria capaz de catalisar o projeto de soerguimento socioeconômico urbano, menos por sua capacidade de investimento e mais por estar, espacial e culturalmente, próximo das coletividades, captando seus anseios e evitando a ruptura social mediante a produção de uma hegemonia articulada entre o público e o privado, o empresariado e o Estado, incorporando movimentos sociais e homogeneizando demandas em direção a um projeto de cidade coeso e virtualmente unitário, monolítico - o que não garantiria a pluralidade dentre os contemplados.

Nesse aspecto, assistimos ao desenvolvimento de propostas de reorganização do processo político e dos procedimentos deliberativos no interior do poder instituído. As instituiçôes, assim, são chamadas a participar de uma concertação em geral assumida previamente como democrática e horizontal, não-hierárquica, em que a prática reflete a assimetria na coalizão de forças. A própria democracia representativa e todos os seus vícios são postos em questão para então serem substituídos por modelos flexíveis, ágeis, informalizados e com controle coletivo reduzido, posto que tornados procedimentos decisórios "eficientes", de uma perspectiva "empresarial". Na transposição entre práticas empresariais de competição e a gestão territorial urbana, resta a pergunta: será que não estamos diante de um processo de esvaziamento (retórico e concreto, no campo da práxis) 
das possibilidades de embate e resolução de questões conflituosas estruturais? Não estamos assistindo à criação de um "modelo" de "política" e de efetivo governo territorializado que, sob o discurso da atuação detida e próxima, eficiente e ágil, despolitiza o embate?

No que diz respeito à reestruturação produtiva, a autora discute os impactos sobre o mercado de trabalho e aponta a flexibilização das relaçōes e das garantias contratuais como evidências da nova dinâmica do capital internacional: as empresas lograriam êxito em migrar, planejar e implantar atividades em territórios que se esforçam para deter características favoráveis, atrativas e "competitivas". Essa competitividade definiria, por sua vez, uma homogeneização crescente das condições objetivas da produção e da acumulação e, ao mesmo tempo, instauraria o paradoxo da impossibilidade de "diferenciação" dos territórios, expostos à mesma lógica de valorização e de escolha locacional. É particularmente dramática essa dimensão do capitalismo flexível - a capacidade de influenciar as institucionalidades e de se converter, em novas bases, numa força atuante no campo de poder do Estado e das políticas urbanas, assim como das econômicas. A própria idéia-motriz da "parceria público-privada", além de ter um caráter de subsídio a interesses privados e de classe, aponta também para uma redefinição das formas de apropriação do produto social e da definição de prioridades.

Trata-se, inegavelmente, de uma prática política (embora essa dimensão lhe seja ritualmente negada, como se fora apenas questão de "eficiência" e "cooperação") de notável hegemonia, ainda que contraditória, uma vez que "delega" a determinadas instâncias do poder estatal a competência de gerir as condições institucionais e a provisão de garantias à acumulação, com claros impactos sobre os poderes locais e a soberania dos Estados-nação. Essa transferência de atribuições não está isenta da histórica assimetria de apropriação do poder político no Estado capitalista.

O estudo de caso apresentado pela autora é o do município do Rio de Janeiro, onde foi contratada consultoria para elaboração do Plano Estratégico da Cidade, na primeira metade dos anos 1990. Esse Plano, elaborado por equipe catalã, é apresentado como elemento fundamental de uma política de ordenamento territorial (que pressupõe concepções de administração pública e de urbanismo) que se pretende catalisadora do soerguimento socioeconômico da cidade, atravessada pela es- tagnaçãa econômica e pela saída de empresas desde os anos 1980. A procedência da consultoria não é casual. Barcelona é, hoje, difusora de um modelo de intervenção e política urbana cuja pretensão é a de recolocar as cidades num contexto de economia globalizada. Essas intenções são vistas como "respostas" à crise que se entende associada à reestruturação produtiva do capital e às formas flexíveis da acumulação: flexibilização, desregulamentação, empreendedorismo e mecanismos de parceria público-privada.

A adoção do Planejamento Estratégico de Cidades apresenta-se como expressão de coalizão de interesses em torno da reconfiguração morfológica e funcional da cidade e da redefinição de suas prioridades administrativas e orçamentárias. Uma série de instrumentos legais é assim efetivada para tornar possíveis a competitividade e a atratividade: operações interligadas, desregulamentação favorável a condomínios ou empreendimentos específicos (hospitais privados, shopping centers, apart-hotéis), alterações do Plano Diretor Urbano, intervenções urbanísticas "pontuais" e "catalíticas" e reorganização administrativa da prefeitura municipal. Em todas essas medidas, está presente a pretensão a atuar nas esferas de decisão e de comunicação da política urbana, promovendo a apropriação privada (com freqüência, empresarial) de nichos do poder via mecanismos relativamente sutis da tomada de decisôes "participativas" e "sustentáveis".

O discurso do desenvolvimento econômico parece ter a função de negociar os termos desiguais da reconfiguração do assentamento historicamente produzido que é a cidade e, no caso específico, de colocar a proeminência da competitividade como valor a cultivar, coletivamente; não mais como o liberalismo burguês faz com a democracia, a partir da abstração da idéia de universalidade, mas como civismo socialmente compartilhado, como estratégia "obrigatória" de reversão da crise pós-globalização, em que a (pós) modernização se apresenta como necessidade e oportunidade.

No Rio de Janeiro, frentes de expansão de algum laissez--faire imobiliário se abrem e mobilizam recursos e adaptaçōes legislativas diversas. A paisagem urbana decorrente incluirá lagoas poluídas por condomínios de luxo, sistemas viários articulando trechos de "cidadelas", por edifícios de gabarito aumentado sob mecanismos "redistributivos" (cujo recurso se converte no financiamento da urbanização do seu próprio entorno) e por in- 
tervenções urbanísticas pontuais limitadas à concepção espetacular da cidade, numa clara apropriação do que há de mais "comportamental" e imagético na idéia de identidade visual urbana das correntes tradicionais do desenho urbano anglo-saxão. Todos esses elementos sugerem, se não uma mudança de paradigma da gestão urbana contemporânea, pelo menos uma nova forma de os capitais privados se reproduzirem na cidade pós-fordista.

O Planejamento Estratégico (antiga técnica militar, depois convertida em modelo empresarial) e a Parceria Público-Privada seriam, portanto, ferramentas com efeito de promoção da acumulação capitalista em bases até certo ponto renovadas, dadas as exigências contemporâneas da produção e dos serviços a ela correlatos, bem como do capital financeirizado. O Planejamento Estratégico opera primordialmente no plano da retórica, dos discursos e da argumentação, uma vez que costuma revestir de articulação intersetorial procedimentos de produção ritualizada de consenso político. As parcerias, por sua vez, se mostram como instrumentos de priorização de investimento em atividades e infra-estruturas rentáveis, em detrimento daqueles - "ultrapassados" - investimentos universalistas do Estado de Bem-Estar Social. A autora coloca uma hipótese provocativa, em caráter provisório, ao final do texto: a promoção dos setores imobiliário, comercial de médio e alto padrão e de serviços avançados não teria relação com o fato de esses buscarem maior rentabilidade e também por estarem ligados mais diretamente à base fiscal dos municípios do que a produção industrial?

Valendo-se do inegável apelo filosófico da crítica ao modernismo funcionalista e suas mazelas, o Planejamento Estratégico, seu urbanismo just in time e seu planejamento urbano flexível representariam uma "neoliberalização" da política urbana. Como tal, exibem contradiçōes entre retórica (a "desregulamentação") e prática concreta (os vários subsídios e prioridades). Analisar a dimensão e, principalmente, os efeitos e o aspecto qualitativo desse modelo contemporâneo de incorporação da política urbana à regulação capitalista não é apenas uma tarefa política, mas parte do processo de construção de conhecimento e de seu rebatimento social. Em que pese o caráter parcial da crítica, próprio do processo de sedimentação e amadurecimento de sua construção, o debate está posto e em curso, para que seja possível identificar os sentidos dos novos modelos de política urbana.

\section{SUSTAINABLE PLACE}

Christine Phillips

West Sussex, England: Wiley-Academy, 2003. 218p.

Roberto Anderson de Miranda Magalhães

Doutorando do Prourb/UfRj e coordenador da Área de Urbanismo do Centro de Arquitetura e Artes da USU

Segundo Roger-Machart (1997), ${ }^{1}$ grande parte da literatura sobre cidades sustentáveis permanece focada nesse conceito, buscando explicar por que e como as cidades deveriam ser sustentáveis. No entanto, haveria pouca exploração acerca dos meios de sua implementação. O livro de Christine Phillips torna-se interessante na medida em que tenta definir um método de avaliação da sustentabilidade urbana e sua aplicação, fornecendo material para uma crítica da "insustentabilidade" das cidades. A autora doutorou-se pelo AA Environment \& Energy Studies Programme entre 1995/1998, na Inglaterra, e sua experiência anterior esteve ligada às artes, tendo trabalhado como perspectivista em vários projetos, como o Victoria \& Alfred Waterfront.

Sustainable place divide-se em duas partes. $\mathrm{Na}$ primeira, a autora apresenta dois estudos de caso: San Giminiano (Itália) e Ludlow (Inglaterra), onde aplica sua metodologia de análise das condiçôes de sustentabilidade. Na segunda parte, apresenta três projetos que têm o mérito de trazer informações úteis para a constituição de um "desenho urbano ecológico". Em ambas as partes, percebe-se que a autora parece crer numa sustentabilidade objetiva, mensurável a partir de indicadores ou construída a partir de projeto.

Citando Yannas (1998), ${ }^{2}$ Phillips relaciona algumas consideraçōes em relação ao microclima das cidades como a atenção à forma das construções, cujas densidade e tipo interferem com os fluxos de ar, a visão do sol e do céu e a área de superfície exposta; sublinha a necessidade de se evitar a "Rua Canyon", já que a proporção entre a largura e a altura das edificações, bem como a sua orientação influenciam as condições de conforto termal e visual, e a poluição; a atenção ao desenho das edificaçôes e à capacidade termal e ao al-

1 ROGER-MACHART, C. The sustainable city - myth or reality? T\&CP, fev. 1997, p.53-5.

2 YANNAS, S. Living with the city. Urban design and environmental sustainability. In: Environmentally Friendly Cities, James and James (London). Proceedings of PLEA (Passive and Low Energy Architecture) international conference, 1998. 